\title{
Animal-related injuries in a resource-limited setting: experiences from a Tertiary health institution in northwestern Tanzania
}

\author{
Japhet M Gilyoma ${ }^{\dagger}$, Joseph B Mabula ${ }^{\dagger}$ and Phillipo L Chalya ${ }^{*}$
}

\begin{abstract}
Background: Animal related injuries are a major but neglected emerging public health problem and contribute significantly to high morbidity and mortality worldwide. No prospective studies have been done on animal related injuries in our setting. This study was conducted to determine the management patterns and outcome of animal related injuries and their social impact on public health policy in the region.
\end{abstract}

Methods: This was a descriptive prospective study of animal related injury patients that presented to Bugando Medical Centre between September 2007 and August 2011. Statistical data analysis was done using SPSS computer software version 17.0.

Results: A total of 452 (8.3\%) animal-related injury patients were studied. The modal age group was 21-30 years. The male to female ratio was 2.1:1. Dog-bites (61.1\%) were the most common injuries. Musculoskeletal (71.7\%) region was the most frequent body region injured. Soft tissue injuries (92.5\%) and fractures (49.1\%) were the most common type of injuries sustained. Only 140 (31.0\%) patients were hospitalized and most of them (97.1\%) were treated surgically. Wound debridement was the most common procedure performed in $91.2 \%$ of patients. Postoperative complication rate was 15.9\%, the commonest being surgical site infections (SSI) in $55.1 \%$ of patients. SSI was significantly associated with late presentation and open fractures $(P<0.001)$. The overall median duration of hospitalization was 16 days. Patients who had severe injuries, long bone fractures and those with hemiplegia stayed longer in the hospital $(P<0.001)$. Mortality rate was $10.2 \%$ and was significantly high in patients with severe injuries, severe head injury, tetanus and admission SBP $<90 \mathrm{mmHg}(\mathrm{P}<0.001)$. The follow up of patients was poor.

Conclusion: Animal related injuries constitute a major public health problem in our setting and commonly affect the young adult male in their economically productive age-group. Measures towards prevention and proper treatment and follow up are important in order to reduce morbidity and mortality resulting from this form of trauma

Keywords: Animal related injuries, Injury patterns, Outcome, Tanzania

\section{Background}

Animal related injuries are a major but neglected emerging public health problem and contribute significantly to high morbidity and mortality worldwide [1-3]. Human injuries resulting from encounters with domestic and wild animals are increasingly common throughout the world, particularly as ecosystems change and humans

\footnotetext{
*Correspondence: drphillipoleo@yahoo.com

${ }^{\dagger}$ Equal contributors

Department of Surgery, Catholic University of Health and Allied

Sciences-Bugando, Mwanza, Tanzania
}

encroach on previously wild land [4,5]. The growing human population in developing countries such as Tanzania has brought animals and humans into closer physical contact, and prompted higher rates of animal attacks on humans $[5,6]$. This appears increased during times of drought and decreased availability of crop food, as well as when humans venture off frequently used paths [5-7].

Animals can cause injuries by various mechanisms that include bite, sting, crush, gore, stomp, buck off, fall on, peck, or scratch. In addition to inflicting traumatic 
injuries, animals transmit numerous zoonotic infections $[8,9]$. The threat of animal attacks on people is still a huge medico-social problem as these attacks result in millions of injuries and thousands of deaths all over the world [9-11]. Fortunately, the majority of such injuries are minor. It is estimated that about $60 \%$ of animal attacks lead to such mild injuries that the ambulatory treatment is sufficient, or the injured do not call for medical help at all [12].

However, many injuries remain undocumented and many people die, primarily in third-world countries, before receiving adequate medical care [13]. Besides, the medical and financial costs from both fatal and non-fatal animal encounters have a significant impact on public health [8]. Animal bite wounds are generally considered dirty or contaminated, and their treatment is difficult because of the risk of infection, especially in extensive injuries [14-17].

The outcome of treatment of animal related injuries may be poor especially in developing countries due to late presentation, lack of advanced pre-hospital care system and trauma centers and ineffective ambulance system for transportation of patients from the site if injury to hospital continues to be an area of neglect that prevents optimal trauma care [18].

There is paucity of information in most developing countries on animal related injuries where greater emphasis has been placed on injuries related to Road traffic accidents, which are more common. Given the proximity of our northwestern Tanzania hospital to Lake Victoria, Lake Tanganyika, and the Serengeti National Park, and presentation of several patients attacked by both domestic and wild animals with variety of complex injuries, we thought it was necessary to report our experience in the management of animal related injuries, outlining the management patterns and outcome of animal related injuries and their social impact on public health policy in the region.

\section{Methods}

\section{Study design and setting}

This was a five year descriptive prospective study of animal related injury patients that presented to the Accident and Emergency of Bugando Medical Centre (BMC) between September 2007 and August 2011. Bugando Medical Centre (BMC) is a referral, consultant and teaching hospital for the Catholic University of Health and Allied Sciences-Bugando (CUHAS-Bugando) and other paramedics and it is located in Mwanza city in the northwestern part of the United Republic of Tanzania. It is situated along the shore of Lake Victoria and has 1000 beds. BMC is one of the four largest referral hospitals in the country and serves as a referral centre for tertiary specialist care for a catchment population of approximately
13 million people from neighboring. There is no trauma centre or established advanced pre-hospital care in Mwanza city as a result all trauma patients are referred to $\mathrm{BMC}$ for expertise management.

\section{Study subjects}

The subjects of this study included all patients of all age group and gender that presented to BMC with animal related injuries during the study period. Patients who failed to give proper information and those who had no relative to consent for the study were excluded from the study.

Recruitment of patients to participate in the study was done at the A \& E department. Patients were screened for inclusion criteria and those who met the inclusion criteria were, after informed consent to participate in the study, consecutively enrolled into the study.

Patients with severe injuries were first resuscitated in the A\&E department according to Advanced Trauma Life Support (ATLS). From the A \& E department, patients were taken into the surgical wards or the intensive care unit (ICU) from where necessary investigations were completed and further treatment was instituted. Patients with open wounds and those with evidence of abdominal visceral injuries were taken to theatre for surgical intervention. Severe head injury patients with evident of space occupying lesions were also taken to theatre for possible craniotomy or burr holes and evacuation of haematoma. The severity of injury was determined using the Kampala trauma score II (KTS II) [19]. Severe injury consisted of a KTS II $\leq 6$, moderate injury 7-8, and mild injury 9-10. Patients with head injuries were classified according to Glasgow Coma Scale (GCS) into: severe (GCS 3-8), moderate (GCS 9-12) and mild (GCS 13-15). An initial systolic blood pressure (SBP) on each patient was also recorded on admission. Routine investigations including hematological (hemoglobin, blood grouping \& cross-matching), biochemical (serum creatinine \& serum electrolytes) and radiological ( $x$-rays of the chest \& abdomen, abdominal ultrasound and CT scan) were performed on admission.

Depending on the type of injury, the patients were treated either conservatively or by surgery. All patients were followed up till discharged or death. This information was collected using a pre-tested questionnaire. Included in the questionnaire were socio-demographic data (age, sex, education and occupation), mechanism of injury, prehospital care, injury-arrival interval, admission haemodynamic parameters (e.g. systolic blood pressure and pulse rate), type and pattern of injury, trauma scores, body region injured, treatment offered, complications of treatment. Outcome variables were length of hospital stay, mortality and disability. 


\section{Statistical data analysis}

Statistical data analysis was done using SPSS software (Statistical Package for the Social Sciences, version 17.0, SPSS Inc, Chicago, Ill, USA). Data was summarized in form of proportions and frequent tables for categorical variables. Continuous variables were summarized using means, median, mode and standard deviation. P-values were computed for categorical variables using Chisquare $\left(\chi^{2}\right)$ test and Fisher's exact test depending on the size of the data set. Independent student $t$-test was used for continuous variables. Multivariate logistic regression analysis was used to determine predictor variables that are associated with outcome. A p-value of less than 0.05 was considered to constitute a statistically significant difference.

\section{Ethical considerations}

The study was carried out after the approval by the department of surgery and BMC/CUHAS-Bugando ethics review board. An informed written consent was sought from patients or relatives.

\section{Results}

\section{Socio-demographic data}

During the period of study, a total of 54940 trauma patients were seen at BMC. Of these, 452 patients representing $8.3 \%$ of all trauma admissions had animal related injuries and these made the study population. The age of patients at presentation ranged from 9 to 86 years with a median age of 28 years. The peak age incidence was in the 21-30 years age group accounting for 248 (54.9\%) patients. Males were 304 (67.3\%) and females were 148 (32.7\%), giving a male to female ratio of 2.1:1. Most of patients, $376(83.2 \%)$ had either primary or no formal education and more than eighty percent of them were unemployed. Peasants and fisherman were the majority of animal related injury victims accounting for $302(66.8 \%)$ and $100(22.1 \%)$ patients respectively. The remaining $50(11.1 \%)$ patients were school children, housewife or civil servants. The majority of patients, $322(71.2 \%)$ came from the rural areas located a considerable distance from Mwanza City and more than ninety percent of them had no identifiable health insurance.

\section{Circumstances of the injury}

The vast majority of patients, $356(78.8 \%)$ sustained blunt injuries and the remaining 96 (21.2\%) patients had penetrating injuries. The blunt to penetrating injuries ratio was 3.7: 1. The most prominent injuries were due to domestic animals accounting for $71.2 \%$ of cases (Table 1). Of the domestic animal related injuries, dogbites were the most common injuries and were found to be greater in children compared to adults ( $p<0.001)$,
Table 1 Distribution of animal related injuries according to animal species

\begin{tabular}{llll}
\hline Animal species & $\begin{array}{l}\text { Mechanism of } \\
\text { injury }\end{array}$ & $\begin{array}{l}\text { Number of } \\
\text { patients }\end{array}$ & Percentage \\
\hline Domestic animals & B22 & $\mathbf{7 1 . 2}$ \\
- Dog & Bite, scratches & 276 & 61.1 \\
- Cow & Attacking with horns & 15 & 3.3 \\
- Cats & Bite, scratches & 9 & 2.0 \\
- Donkey & Kicks, fall & 7 & 1.5 \\
Snake & Bite, Invenomation & $\mathbf{6 2}$ & $\mathbf{1 3 . 7}$ \\
Wild animals & & $\mathbf{3 1}$ & $\mathbf{6 . 9}$ \\
- Hyena & Bite, scratches & 12 & 2.7 \\
- Leopard & Bite, scratches & 9 & 2.0 \\
- Elephant & knocking over, & 5 & 1.1 \\
& Attacking with & & \\
- Vervet monkey & horns, battering & & 0.9 \\
- Lion & Bite & 4 & 0.1 \\
Aquatic animals & & 1 & $\mathbf{1 . 5}$ \\
- Crocodiles & Bite, crush & 6 & 1.3 \\
Hippopotamus & Bite, knocking over & 1 & 0.2 \\
Insects & Sting & $\mathbf{1 6}$ & $\mathbf{3 . 5}$ \\
Unspecified & Bite, scratches etc & $\mathbf{1 4}$ & $\mathbf{0 . 9}$ \\
animal & & & \\
\hline
\end{tabular}

whereas other injuries were greater in adults than in children $(\mathrm{p}<0.001)$.

Following the injury events, none of the patients received any pre-hospital care and majority of them (382, 84.5\%) were brought to the A \& E department by relatives, friends or Good Samaritan, 67 (14.8\%) by police and only three $(0.8 \%)$ patients were brought in by ambulance.

\section{Injury characteristics}

Musculoskeletal (extremities) region was the most common body region injured affecting $71.7 \%$ of patients (Table 2). Isolated injuries occurred in 402 (88.9\%) patients while $50(11.1 \%)$ patients had multiple injuries. Open wounds (i.e. bruises, abrasions, lacerations, punctured, avulsion, crush wounds etc) and fractures were the most common type of injuries sustained accounting for $92.5 \%$ and $49.1 \%$ of cases respectively (Table 3 ). Allergic reactions caused by insect stings were recorded in four patients.

According to Kampala Trauma Score II (KTS II) (Table 4), the majority of patients sustained mild injuries (KTS II = 9-10) in 312 (69.0\%). moderate injuries (KTS II $=7-8$ ) and severe injuries (KTS II $\leq 6)$ were recorded in $82(18.2 \%)$ and $58(12.8 \%)$ patients respectively.

The Glasgow coma scale (GCS) indicated that 76 $(16.8 \%)$ patients sustained head injuries. Of these, 41 (54.0\%) sustained mild head injury, 20 (26.3\%) patients 
Table 2 Site of injuries among the victims

\begin{tabular}{lll}
\hline Site of injury & Number of patients & Percentage \\
\hline Musculoskeletal (extremities) & 324 & 71.7 \\
- Lower limbs & $(192)$ & $(59.3)$ \\
- Upper limbs & $(132)$ & $(40.7)$ \\
Abdomen & 118 & 26.1 \\
Chest & 89 & 19.7 \\
Head & 76 & 16.8 \\
Pelvis & 17 & 3.8 \\
Spines & 12 & 2.7 \\
Genitalia & 9 & 1.9 \\
\hline
\end{tabular}

Note: Some patients had more than one site of injuries.

sustained moderate head injury and 15 (19.7\%) patients had severe head injury. The majority of patients, 398 (88.1\%) had systolic blood pressure (SBP) > $90 \mathrm{mmHg}$ on admission and the remaining 54 (11.9\%) patients had SBP of $90 \mathrm{mmHg}$ and below.

\section{Admission patterns and treatment}

Most of patients $(296,65.5 \%)$ reported within 24 hours after injury. The time interval between injury and arrival to the A \& E department ranged from 2 hours to 5 days with a median of 22 hours. The waiting time, defined as the time interval taken from reception at the A \& E department and reception of treatment ranged from 30 minutes to 10 hours with a median of 3.00 hours. The majority of patients, 302 (66.8\%) were attended to within 6 hours of arrival to the A \& E department. Most of animal related injuries, $312(69.0 \%)$ were so mild that after conservative (non-surgical) treatment (such as wound dressing, antibiotics, analgesics, tetanus toxoid, antirabies etc) at the $\mathrm{A} \& \mathrm{E}$ department the patients were discharged home. Only $140(31.0 \%)$ patients were hospitalized. Of these, $102(72.9 \%)$ were admitted to the surgical wards and the remaining 38 (27.1\%) were admitted to the intensive care unit (ICU). All patients were administered antibiotics of varying nature at the $\mathrm{A}$ and $\mathrm{E}$ department. Analgesics (parenterally or orally) were also

Table 3 Distribution of patients according to type of injuries

\begin{tabular}{lll}
\hline Type of injury & Frequency & Percentage \\
\hline Open wounds & 418 & 92.5 \\
Fractures & 222 & 49.1 \\
Visceral abdominal injuries & 46 & 10.2 \\
Intracranial hemorrhages & 34 & 7.5 \\
Pneumohemothorax & 12 & 2.7 \\
Traumatic amputations & 10 & 2.2 \\
Other minor injuries & 23 & 5.1 \\
\hline
\end{tabular}

Table 4 Kampala Trauma score

\begin{tabular}{|c|c|c|}
\hline & Description & Score \\
\hline \multirow[t]{3}{*}{ A } & Age (in years) & \\
\hline & $5-55$ & 1 \\
\hline & $<5$ or $>55$ & 0 \\
\hline \multirow[t]{4}{*}{ B } & Systolic blood pressure on admission $(\mathrm{mmHg})$ & \\
\hline & $<89$ & 2 \\
\hline & $89-50$ & 1 \\
\hline & $>49$ & 0 \\
\hline \multirow[t]{4}{*}{ C } & Respiratory rate & \\
\hline & 9-29/minutes & 2 \\
\hline & $>30 /$ minutes & 1 \\
\hline & $\leq 9 /$ minutes & 0 \\
\hline \multirow[t]{5}{*}{ D } & Neurological status & \\
\hline & Alert & 3 \\
\hline & Responds to verbal stimuli & 2 \\
\hline & Responds to painful stimuli & 1 \\
\hline & Unresponsive & 0 \\
\hline \multirow[t]{4}{*}{ E } & Score for serious injury & \\
\hline & None & 2 \\
\hline & One injury & 1 \\
\hline & More than one injury & 0 \\
\hline
\end{tabular}

Kampala Trauma Score II total $=A+B+C+D+E$.

Interpretation.

KTS $\|<6=$ Severe injury.

KTS /I 7-8 = Moderate injury.

KTS $/ /$ 9-10 = Mild injury.

given to all patients. Four hundred and forty (97.3\%) patients received tetanus toxoid and ninety-six (21.2\%) patients received antirabies. Blood transfusion was given to twenty-one $(4.6 \%)$ patients. The majority of patients (136, 97.1\%) who were hospitalized were treated surgically. Wound debridement was the most common procedure performed in $91.2 \%$ of patients (Table 5).

\section{Outcome and follow up of patients}

A total of 98 complications were recorded in 72 (15.9\%) patients the commonest being surgical site infections in accounting for $55.1 \%$ of patients (Table 6). The majority of patients $(34,63.0 \%)$ had polymicrobial bacterial profile. Staphylococcus aureus was the most common organism isolated accounting for $59.3 \%$ of all the bacterial isolates. According to multivariate regression logistic analysis, surgical site infections was significantly high in patients who presented late to the hospital ( $>24$ hours) and those with open fractures $(\mathrm{P}<0.001)$.

The overall length of hospital stay (LOS) for in-patients ranged from 1 day to 138 days with a median of 16 days. The LOS for non-survivors ranged from 1 day to 16 days (median 5 days). The length of ICU stay ranged from 1 to 18 days (median 4 days). Patients who had severe injuries 
Table 5 Type of surgical procedures performed $(\mathrm{N}=136)$

\begin{tabular}{lll}
\hline Type of surgical procedures & Frequency & Percentage \\
\hline Wound debridement & 124 & 91.2 \\
Treatment of fractures & 89 & 65.4 \\
Exploratory laparotomy & 46 & 33.8 \\
$\begin{array}{l}\text { Craniotomy } \pm \text { burr holes/Elevation } \\
\text { of depressed skull fractures }\end{array}$ & 30 & 22.1 \\
Limb amputation & 28 & 20.6 \\
Skin grafting/flaps & 25 & 18.4 \\
Pleural cavity drainage & 12 & 8.8 \\
Other surgical procedures & 8 & 5.9
\end{tabular}

(KTSII < 6), long bone fractures and those with hemiplegia secondary to spinal injuries stayed longer in the hospital $(\mathrm{P}<0.001)$.

Out of 452 patients, 406 (89.8\%) were alive and the remaining forty-six patients died in hospital giving a mortality rate of $10.2 \%$. According to multivariate regression logistic analysis, mortality rate was significantly high in patients with severe injuries (KTSII $<6$ ), severe head injury, tetanus and admission SBP $<90 \mathrm{mmHg}(\mathrm{P}<0.001)$.

Of the survivors, 370 (91.2\%) patients were discharged well, $5(1.2 \%)$ patients were discharged against medical advice (DAMA) and the remaining 31 (7.6\%) patients were discharged with permanent disabilities related to limb amputations, fracture complications, spinal cord injuries with neurological deficit. Only ninety-eight (21.7\%) patients were available for follow-up at 6-12 months and the remaining patients were lost to follow-up.

\section{Discussion}

In this review, animal related injuries occurred in $8.3 \%$ of all trauma admissions, a figure which is significantly higher than that reported by Moini et al [20] in Iran and Nogalski et al [11] in Poland. These differences in the rate of animal related injuries reflect differences in risk

Table 6 Distribution of patients according to treatment complications $(\mathbf{N}=98)$

\begin{tabular}{lll}
\hline Treatment complications & Frequency & Percentage \\
\hline Surgical site infections & 54 & 55.1 \\
Complications of fractures & 38 & 38.9 \\
Peritonitis/abdominal abscess & 6 & 6.1 \\
Complications of amputation stump & 5 & 5.1 \\
Tetanus & 5 & 5.1 \\
Skin grafting failure & 2 & 2.1 \\
Empyema thoracis & 1 & 1.0 \\
Post-traumatic epilepsy & 1 & 1.0 \\
Brain abscess & 1 & 1.0 \\
\hline
\end{tabular}

factors for animal related injuries between the study settings. The high figure of animal related injuries in this study may be due to the large number of patients with mild injuries which needed only ambulatory treatment and discharged.

The rate of the animal related injuries in the present study may be underestimated due to unreported patients, patients who died at scene or who did not reach our hospital because of treatment of minor injuries in private hospitals. A better picture of the magnitude of animal related injuries in our setting requires comprehensive data including police records, hospital admissions, and mortuary records. Better data could support useful policy guidance and help abate these injuries and their related morbidity and mortality.

In agreement with other studies [11,18,20], animal related injuries in our series were found to be most common in the third decade of life. High occurrences of animal related injuries among this age group have been attributed to a wide range of activities engaged in by this class of people. They represent the active group that partakes in high risk-taking activities such as farming, fishing, hunting, butchers, zoo and circus workers. The fact that this group represents economically productive agegroup demands an urgent public policy response.

In our study, males were more affected than females, a finding which is in agreement with other studies $[11,18,20,21]$. Male predominance in the present study probably reflects the greater exposure of males to outdoor activities such as farming, fishing and hunting. Identification of risk taking behavior among trauma patients has potential significance for the prevention of injuries.

The majority of patients in this study came from the rural areas located a considerable distance from the study area. This is in contrast to Moini et al [20] who reported that animal related injuries affected both rural and urban dwellers. Farmers in rural areas are at high risk of being attacked by either wild, domestic, aquatic animals or snakes.

Previous studies conducted in the United States of America reveal that animals are one of the main causes of injuries in the farming industry [22,23], which is similar to what was found in our series. This observation is at variant with Moini et al [20] who reported that animal-related injuries were more common in house wives than farmers. The finding that more than eighty percent of victims of this form of trauma had no definable source of private or governmental health care insurance at the time of their injury calls for urgent public policy response.

The prehospital care of trauma patient has been reported to be the most important factor in determining the ultimate outcome after the injury [24]. None of our 
patients had pre-hospital care; as a result the majority of them were brought in by relatives, Good Samaritan and police who are not trained on how to take care of these patients during transportation. The lack of advanced pre-hospital care and ineffective ambulance system for transportation of patients to hospitals are a major challenges in providing care for trauma patients in our environment and have contributed significantly to poor outcome of these patients.

Late presentation following injury is a common phenomenon in most developing countries including ours and is usually associated with increased rate of complications [18]. The majority of our patients presented early within 24 hours of their injuries. This finding is in agreement with other studies [18,25]. Early presentation in our study reflects the low complication rate in our patients.

In our study, dog bite was the most common cause of injuries and commonly affected children more than adult. This finding is in agreement with several studies that indicated dogs as the primary animal species implicated in animal related injuries ranging from 63-80\% [26], but contrary to other studies which reported that equestrian traumas are common $[27,28]$. Higher dog attacks in children are thought to be attributable to their size and the proximity of their face to the dogs' mouth, and these attacks are generally related to the children's interaction with the dog, possibly provoking the attack [29].

Given the proximity of our northwestern Tanzania hospital to Lake Victoria, Lake Tanganyika, and the Serengeti National Park, one would expect large number of injuries resulting from aquatic and wild animals. The low rate of injuries from aquatic and wild animals in our study can be explained by the fact that the majority of patients sustaining these severe injuries may have died before reaching the Accident and Emergency department. These animals can produce severe injuries by grasping victims with their powerful jaws and dragging them underwater, where they roll while crushing their prey [18].

In keeping with other studies [30,31], the majority of injuries in the present study were in the lower and upper limbs. Attempts at using, the foot and hand to avoid animal bite may be the possible reason for these parts being affected more. The other thought is that animals may be at ease to attack moving body parts [14,15,31].

The type of wounds in injuries resulting from animal attack can range from minor bruises to more extensive injuries like punctured wounds, avulsions, amputations and separation of a pedunculated flap [18,32]. In this study, open wounds such as bruises, abrasions, lacerations, punctured, avulsion, crush wounds etc and fractures were the most common type of injuries sustained. Limb amputation was reported in only $2.2 \%$ of cases mainly due to large wild and aquatic animals. Similar observation was reported previously by Chalya et al [18] at the same institution.

It has been estimated that about $60 \%$ of animal attacks lead to such mild injuries that the ambulatory treatment is sufficient, or the injured do not call for medical help at all $[22,33]$. The majority of patients in our series sustained mild injuries which is comparable with other studies $[18,22]$. The large number of patients with mild injuries in this study may be responsible for the low rate of hospitalization and complications among these patients.

The principles of management of wounds resulting from animal attacks include cleaning and debriding the wound, consideration of prophylactic antibiotics, treatment of infectious complications when they develop and appropriate use of tetanus vaccination $[17,18,32]$. Whereas minor wounds are usually treated conservatively with prophylactic antibiotics, analgesics, tetanus toxoid and cleaning of wounds with normal saline and apply dressing, extensive wounds require operative procedures mainly debridement and primary or delayed primary closure.

In our study, the vast majority of hospitalized patients were treated surgically and surgical wound debridement with either primary or delayed closure was the most frequent surgical procedure performed.

In this study, wound infection was the most common complication and majority of patients had polymicrobial bacterial profile. Staphylococcus aureus was the most common organism isolated. Similar observation was also noted previously at the same study area by Chalya et al [18] reflecting no change of bacterial profile in this region.

The current study had a mortality rate of $10.2 \%$, which is higher than that reported by others [20]. High mortality rate in our study was recorded in patients with severe injuries, severe head injury, tetanus and shock on admission.

The length of hospital stay (LOS) has been reported to be an important measure of morbidity among trauma patients. Prolonged hospitalization is associated with an unacceptable burden on resources for health and undermines the productive capacity of the population through time lost during hospitalization and disability. Our figures for the overall median LOS in the present study were higher than that reported by others [11,20,31]. Patients who had severe injuries, long bone fractures and those with hemiplegia secondary to spinal injuries stayed longer in the hospital. However, due to the poor socioeconomic conditions in Tanzania, the duration of inpatient stay for our patients may be longer than expected.

Generally, the overall outcome of our patients was good as more than ninety percent of patients (survivors) were discharged well without permanent disabilities.

Self discharge by patient against medical advice is a recognized problem in our setting and this is rampant, 
especially amongst trauma patients [34]. Similarly, poor follow up visits after discharge from hospitals remain a cause for concern. These issues are often the results of poverty, long distance from the hospitals and ignorance. Delayed presentation, inadequate ICU space, discharge against medical advice, and the large number of loss to follow up were the major limitations of this study. Another potential limitation was that the analyzed group of patients was treated at a single medical centre. For that reason, the results may not be adequate for the whole population in this part of Tanzania. However, despite these limitations, the study has provided local data that can be utilized by health care providers to plan for preventive strategies as well as establishment of management guidelines for patients with animal related injuries. The study also provides a comparable data to the other parts of the world in the field of animal related injuries. The challenges identified in the management of these patients in our setting need to be addressed, in order to deliver optimal trauma care for the victims of animal related injuries.

\section{Conclusion}

Animal related injuries in this region affect predominantly young adult males in their economically productive age - group. The severe injury group requires great hospital resources and show high morbidity, mortality and permanent disability. Thus constituting a major health regional problem, they require closer observation and analysis from the decision makers to provide appropriate health promotion and prevention measures as well as assuring great resources for their proper treatment.

\section{Competing interests}

The authors declare that they have no competing interests.

\section{Authors' contributions}

JMG conceived the study, participated in the design and coordination of the study and drafted the manuscript. JBM and PLC contributed in study design, literature search, data analysis, manuscript writing and editing. In addition PLC submitted the manuscript. All the authors read and approved the final manuscript.

\section{Acknowledgements}

The authors acknowledge all those who participated in the preparation of this manuscript and those who were involved in the care of our study patients. Special thanks go to our Senior House Officer for their support during data collection.

Received: 28 November 2012 Accepted: 29 January 2013 Published: 1 February 2013

\section{References}

1. Smith PF, Meadowcroft AM, May DB: Treating mammalian bite wounds. J Clin Pharm Ther 2000, 25:85-99.

2. Centers for Disease Control and Prevention: Nonfatal dog bite-related injuries treated in hospital emergency departments-United States, 2001. MMWR Morb Mortal Wkly Rep 2003, 52:605-610.

3. Bower MG: Managing dog, cat, and human bite wounds. Nurse Pract 2001, $26: 36-8$.
4. Langley RL: Fatal animal attacks in North Carolina over an 18-year period. Am J Forensic Med Pathol 1994, 15:160-7.

5. Mitchell K, Kotecha VR, Chandika AB: Bush animal attacks: management of complex injuries in a resource-limited setting. World J Emerg Surg 2011, 6:43.

6. Thirgood S, Woodroffe R, Rabinowitz A: The impact of human-wildlife conflict on human lives and livelihoods. In People and wildlife: conflict and coexistence? Edited by Woodroffe R, Thirgood S, Rabinowitz A. Cambridge, UK: Cambridge University Press; 2005:13--26.

7. National Geographic Animals. [http://animals.nationalgeographic.com/ animals/mammals/hyena/\#]

8. Langley RL: Animal-Related Fatalities in the United States-An Update. Wilderness Environ Med 2005, 16:67-74.

9. Overall KL, Love M: Dog bites to humans-demography, epidemiology, injury, and risk. J Am Vet Med Assoc 2001, 218:1923-1934.

10. $\mathrm{WHO}$ in the Eastern Mediterranean Region: Annual Report of Eastern Mediterranean Regional Office. Alexandria: World Health Organization; 2003.

11. Nogalski A, Jankiewicz L, Cwik G, Karski J, Matuszewski L: Animal related injuries treated at the department of trauma and emergency medicine, Medical University of Lublin. Ann Agric Environ Med 2007, 14:57-61.

12. Purschwitz M: Epidemiology of agricultural injuries and illnesses. In Safety and Health in Agriculture. Edited by Langley R, McLymore R, Meggs W, Roberson G. Rockville: Forestry and Fisheries. Government Institute Press; 1997:215-231.

13. Chippaux JP: Snake-bites: appraisal of the global situation. Bull World Health Organ 1998, 176:515-524.

14. Aigner N, Konig S, Fritz A: Bite wounds and their characteristic position in trauma surgery management. Unfallchirurg 1996, 99:346-50.

15. Abuabara AA: review of facial injuries due to dog bites. Med Oral Pathol Oral Cir Bucal 2006, 11:348-50.

16. Wolff KD: Management of animal bite injuries of the face: experience with 94 patients. J Oral Maxillofac Surg 1998, 56:838-43.

17. Jennifer B, Marion LW: Management of bite injuries. Aust Prescr 2006 29:6-8.

18. Chalya PL, Mchembe MD, Gilyoma JM, Mabula JB, Chandika AB, Mshana SE: Bite injuries at Bugando Medical Centre, Mwanza Tanzania: A five year experience. East Cent. Afr. J. Surg 2011, 16(1):46-52.

19. Mutooro SM, Mutakooha E, Kyamanywa P: A comparison of Kampala trauma score II with the new injury severity score in Mbarara University eaching Hospital in Uganda. East Cent Afr J Surg 2010, 15(1):62-70.

20. Moini M, Peyvandi AA, Mohammad Reza Rasouli MR, Khaji A, Kakavand M, Eghbal P, Peyvandi H, Molavi B: Pattern of Animal-Related Injuries in Iran. Acta Med Iran 2011, 49(3):163-168.

21. Gautret P, Schwartz E, Shaw M, Soula G, Gazin P, Delmont J, Parola P, Soavi MJ, Matchett E, Brown G, Torresi J: Animal-associated injuries and related diseases among returned travellers: A review of the GeoSentinel Surveillance Network. Vaccine 2007, 25(14):2656-2663.

22. Schwab RA, Powers RD: Puncture wounds and mammalian bites. In Emergency Medicine. Edited by Tintinalli JE, Kelen GD, Stapczynski JS. New York, NY: McGraw-Hill; 2004:327-328.

23. Busch HM Jr, Cogbill TH, Landercasper J, Landercasper BO: Blunt bovine and équine trauma. J Trauma 1986, 26(6):559-60.

24. Liberman M, Mulder D, Lavoie A, Denis R, Sampalis JS: Multicenter Canadian study of prehospital trauma care. Ann Surg 2003, 237(2):153-60.

25. Steele MT, Ma OJ, Nakase J, Moran GJ, Mower WR, Ong S, Krishnadasan A, Talan DA: Emergency ID NET Study Group: Epidemiology of animal exposures presenting to emergency departments. Acad Emerg Med 2007, 14(5):398-403.

26. ONeil ME, Mack KA, Gilchrist J: Epidemiology of non canine bite and sting injuries treated in U. S. emergency departments, 2001-2004. Public Health Rep 2007, 122(6):764-775.

27. Ball CG, Ball JE, Kirkpatrick AW, Mulloy RH: Equestrian injuries: incidence, injury patterns, and risk factors for 10 years of major traumatic injuries. Am J Surg 2007, 193(5):636-40.

28. Yim WW, Yeung JH, Mak PS, Graham CA, Lai PB, Rainer TH: Five year analysis of Jockey Club horse-related injuries presenting to a trauma centre in Hong Kong. Injury 2007, 38(1):98-103.

29. Ozanne-Smith J, Ashby K, Stathakis VZ: Dog bite and injury preventionanalysis, critical review, and research agenda. In J Prev 2001, 7:321-326.

30. Mengistu F, Hussen K, Ali A, Getahun G, Sifer D: Dog bite as a public health concern in Addis Ababa. Ethiop. J. Health Dev. 2011, 25(1):58-60. 
31. Hon KL, Fu CC, Chor CM, Tang PS, Leung TF, Man CY: Issues associated with dog bite injuries in children and adolescents assessed at the emergency department. Pediator Emerg Care 2007, 23(7):445-9.

32. Callaham M, French SP, Tetlow P, Rees P: Bites and injuries inflicted by mammals. In Wilderness Medicine: Management of Wilderness and Environmental Emergencies. 3rd edition. Edited by Auerbach PS. Mosby-Year Book: St. Louis; 1995:943.

33. Donkor P, Bankas DO: A study of primary closure of human bite injuries to the face. J Oral Maxillofac Surg 1997, 55:479-481.

34. Ohanaka EC: Discharge against medical advice. Trop Doc 2002, 32:149-151.

doi:10.1186/1749-7922-8-7

Cite this article as: Gilyoma et al:: Animal-related injuries in a resourcelimited setting: experiences from a Tertiary health institution in northwestern Tanzania. World Journal of Emergency Surgery 2013 8:7.

\section{Submit your next manuscript to BioMed Central and take full advantage of:}

- Convenient online submission

- Thorough peer review

- No space constraints or color figure charges

- Immediate publication on acceptance

- Inclusion in PubMed, CAS, Scopus and Google Scholar

- Research which is freely available for redistribution 